\title{
Products of Orange II Biodegradation by Enterococcus faecalis ID6017 and Chryseobacterium indologenes ID6016
}

\author{
VINCENTIA IRENE MEITINIARTI ${ }^{*}$, ENDANG SUTARININGSIH SOETARTOํ, \\ KRIS HERAWAN TIMOTIUS ${ }^{2}$, AND EKO SUGIHARTO ${ }^{3}$ \\ ${ }^{1}$ Biology Faculty, Universitas Gadjah Mada, Bulaksumur, Yogyakarta 55281, Indonesia \\ ${ }^{2}$ Biology Faculty, Universitas Kristen Satya Wacana, Jalan Diponegoro 52-60, Salatiga 50711, Indonesia \\ ${ }^{3}$ Department of Chemistry, Universitas Gadjah Mada, Bulaksumur, Yogyakarta 55281, Indonesia
}

\begin{abstract}
Chryseobacterium indologenes and Enterococcus faecalis were isolated from activated sludge of textile wastewater treatment plant. These bacteria had the ability to decolorize several azo-dyes. Degradation of azo dyes was initiated by decolorization (reduction of azo bond) which occurred in anaerobic condition. In this study, we focussed on biodegradation of Orange II by pure culture of C. indologenes ID6016 and E. faecalis ID6017, and to determine the metabolite products of Orange II degradation. The degradation of Orange II by both bacteria was carried out in batch experiments using liquid medium containing $80 \mathrm{mg} / \mathrm{l}$ Orange II, under sequential static agitated incubation. During the bacterial growth under static incubation $(6 \mathrm{~h}), 66.1 \mathrm{mg} / \mathrm{l}$ Orange II were decolorized by $35.54 \mathrm{mg} / \mathrm{l}$ biomass of $E$. faecalis ID6017, but no decolorization found with $C$. indologenes ID6016. Based on HPLC results, the decolorized Orange II products were identified as sulfanilic acid and amino-naphthol. These metabolites were probably used or degraded by $C$. indologenes ID6016 under agitated incubation.
\end{abstract}

Key words: Enterococcus faecalis ID6017, Chryseobacterium indologenes ID6016, Orange II, biodegradation

Orange II is one of synthetic azo dyes, the largest chemical class of dyes with the greatest variety of colors, which has been widely used for textile, food, and cosmetics. The compound has an azo bond $\left(\mathrm{R}_{1}-\mathrm{N}=\mathrm{N}-\mathrm{R}_{2}\right)$, where $\mathrm{R}_{1}$ and $\mathrm{R}_{2}$ are aromatic groups, which in some cases, can be substituted by sulphonated groups (Zollinger 1987). Orange II is synthesized by diazotized reaction of sulfanilic acid with amino naphthol. Several others of azo dyes are either toxic, mutagenic or carcinogenic, and have a potential health hazard (Chung et al. 1981; Gottlieb et al. 2003).

In the dyeing process, approximately $10-15 \%$ of the dyes are released into the environment through effluent of industry. The azo dyes are generally unaffected by conventional activated sludge process under aerobic condition and usually they are found in the effluent of wastewater treatment (WWT) (Supaka et al. 2004). In several cases, conventional waste water treatment of azodyes containing wastewater combined with physical or chemical treatment, such as biosorption, chemical coagulation, and electrochemical method, could produce decolorized effluent (Lin and Peng 1996; Lin and Chen 1997; Kargi and Ozmihei 2004). However, those approaches often have problems, caused by chemical sludge which is produced from these treatments. Therefore, there is still a demand to develop alternative means of dye decolorization, such as innovative biological methods that are able to provide a more natural and complete clean-up of the pollutants in a more economical way (Coughlin et al. 2003).

Although the azodyes are usually resistant to microbial degradation under conditions normally found in wastewater treatment plants, several microorganism are able, under certain environmental conditions, to transform azodyes to

${ }^{*}$ Corresponding author, Biology Faculty, Universitas Kristen Satya Wacana, Jalan Diponegoro No 52-60, Salatiga 50711, Indonesia; Phone: +62-298-321212 ext. 305, Fax: +62-298-321433, E-mail: irene_meiti@yahoo.com non-colored products or even to completely mineralize them (Stolz 2001). Several species of bacteria, either mixed or single culture, for examples Pseudomonas luteola (Hu 2001; Chang et al. 2001), Sphingomonas sp. (Kudlich et al. 1996; Coughlin et al. 1997; Keck et al. 1997; Russ et al. 2000), Bacillus subtilis (Zissi and Lyberatos 1996), and coculture of Hydrogenophaga palleronii and Agrobacterium radiobacter (Dangmann et al. 1996; Blümel et al. 1998) have been reported to have the ability to decolorize azodyes. The bacterial ability to decolorize azo dyes varies from 20 to $200 \mathrm{mg} / \mathrm{l}$ azodye concentration. Sphingomonas sp. strain 1CX has an ability to decolorize $20 \mathrm{mg} / \mathrm{l}$ Orange II, Acid Orange 8, Acid Orange 10, Acid Red 4, or Acid Red (Coughlin et al. 1997). Whereas, Pseudomonas luteola has an ability to decolorize Reactive Red up to concentration of $200 \mathrm{mg} / \mathrm{l}$ (Chang et al. 2001).

Chryseobacterium indologenes and Enterococcus faecalis were used as bacterial models for dye decolorization. Those bacteria were isolated from activated sludge of textile wastewater treatment plant (Liem 1997; Setiabudi 1997). The bacteria have the ability to decolorize several dyes such as Amaranth, Reactive Red, Yellow, and Blue (Meitiniarti and Timotius 2003).

In the mixed culture of $C$. indologenes and E. faecalis, various kinds of azodyes were decolorized faster than in a single bacterial culture. $C$. indologenes was not able to decolorize these dyes (Timotius et al. 2002). There is no information of the roles of both bacteria on the azodyes degradation. Orange II was used as a model substrate of azodye degradation. Coughlin et al. (1999) reported that Orange II can be degraded into Sulfanilic acid, which can easily be detected chromatographically, and 1-amino-2naphthol, which undergoes rapid auto oxidation. Chemical structure of Orange II and products of Orange II decolorization by Orange II reductase were shown in Fig 1. 


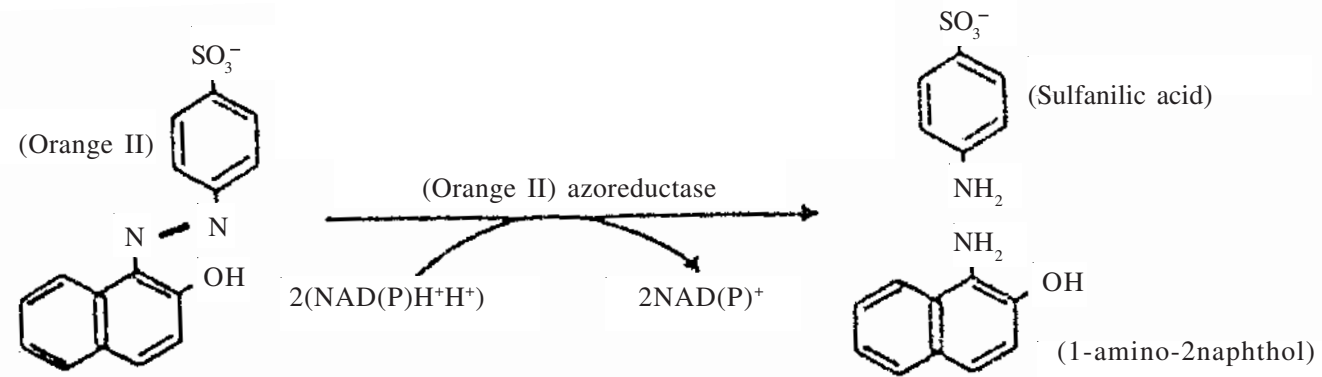

Fig 1 Chemical reaction of Orange II decolorization by Orange II reductase (Zimmermann et al. 1982).

In this study, we focussed on biodegradation of Orange II by pure culture of $C$. indologenes ID6016 and E. faecalis ID6017, grown on a semi-synthetic medium. The aims of this research were to investigate degradation ability of both bacteria and determine the metabolite products of Orange II degradation.

\section{MATERIALS AND METHODS}

Microorganism and Culture Condition. E. faecalis ID6017 and $C$. indologenes ID6016 were obtained from Laboratory of Microbiology, Faculty of Biology, Satya Wacana Christian University, Salatiga, Central Java, Indonesia. Both bacterial culture were maintained and cultivated on slant media of Trypticase Soy Agar (TSA) at room temperature and sub-cultured every two weeks.

The bacteria were grown on liquid basal media consists of $0.90 \mathrm{~g}$ of glucose (glucose was omitted for $C$. indologenes culture), $0.25 \mathrm{~g}$ of $\mathrm{MgSO}_{4} \cdot 7 \mathrm{H}_{2} \mathrm{O}, 1.98 \mathrm{~g}$ of $\left(\mathrm{NH}_{4}\right)_{2} \mathrm{SO}_{4}, 5.55 \mathrm{~g}$ of $\mathrm{K}_{2} \mathrm{HPO}_{4}, 2.13 \mathrm{~g}$ of $\mathrm{KH}_{2} \mathrm{PO}_{4}, 0.25 \mathrm{~g}$ of yeast extract, and 11 of aquadest. Orange II (Merck, CI Acid Orange 7, CI $15510, \mathrm{MW}=440.41$ ) was used in concentration of $80 \mathrm{mg} \mathrm{l}^{-1}$.

Bacterial Cultivation for Dye Degradation Assay. Each of $48 \mathrm{~h}$ TSA slant culture E. faecalis ID6017 and $C$. indologenes ID6016 was inoculated in basal medium without Orange II in $500 \mathrm{ml}$ Erlenmeyer flasks. Cultures were incubated $24 \mathrm{~h}$ on shaker with $150 \mathrm{rpm}$ agitation to reach $\mathrm{OD}_{600 \mathrm{~nm}}=0.3$. These cultures were called as pre-cultures.

The growing vessels contained of basal medium with Orange II were inoculated with $10 \%$ (v/v) of each pre-culture separately and closed with rubber stopper. Cultures were incubated at room temperature, under static condition for 6 $\mathrm{h}$, followed by $150 \mathrm{rpm}$ agitation for $12 \mathrm{~h}$. Before agitation, 80 $\mathrm{ml}$ of the E. faecalis culture was filtered using membrane filter in $2 \mu \mathrm{m}$ diameter and then inoculated aseptically using $20 \mathrm{ml}$ of $C$. indologenes ID6016 $48 \mathrm{~h}$ pre-culture.

Samples were harvested every two hours followed by centrifugation at $3326 \mathrm{~g}$ for $30 \mathrm{~min}$ to separate supernatant and cell mass (biomass). The supernatant was used for determining the dye concentration. The dye concentration was determined by spectrophotometric method at $\lambda_{\max }$ $(482 \mathrm{~nm})$. The cell mass after twice washing, was resuspended into initial volume and measured by turbidimetric method at $\lambda_{600 \mathrm{~nm}}$. The dye concentration was determined by a standard curve of absorbance against dye, meanwhile, biomass concentration was determined by a standard curve of optical density against biomass concentration (cell dry weight). Both measurements of absorbance and optical density were done in a Shimadzu UV-Vis 1201 Spectrophotometer. The ability of both bacterial strains to decolorize Orange II was determined by subtracting the initial dye concentration with the lowest concentration from samplings. The growth of E. faecalis ID6017 and C. indologenes ID6016 was determined by calculating its specific growth rate and biomass production.

In the initial time of culture, after decolorization $(\mathrm{t}=6 \mathrm{~h})$, and at the end of culture ( $\mathrm{t}=12 \mathrm{~h})$, the culture supernatant was analyzed to detect product degradation of Orange II by HPLC.

HPLCAnalysis of Degraded Metabolites (Modification of Supaka et al. 2004). The degraded metabolites were analyzed using HPLC Shimadzu model LC-3A chromatograph, equipped with UV-detector and ODS column $(150 \mathrm{~mm}$ X $8 \mathrm{~mm}$ ). The supernatant culture of E. faecalis ID61017 and C. indologenes ID61016 was injected to HPLC. The mobile phase composed of methanol and acetic acid $0.6 \%$ (vol/vol) $=60: 40$ with the flow rate of $0.7 \mathrm{ml} \mathrm{min}^{-1}$ was applied. The eluent was monitored by UV absorption at $276 \mathrm{~nm}$.

\section{RESULTS}

The Growth of $E$. faecalis ID61017 and $C$. indologenes ID61016 and Their Ability to Degrade Orange II. E. faecalis ID6017 and C. indologenes ID6016 could grew in Orange II containing media, under static incubation. As shown in Table 1 , E. faecalis grown faster $(\mu=0.19)$ and produced more biomass $(35.54 \mathrm{mg}$ ) than $C$ indologenes $(\mu=0.16$ and produced $24.11 \mathrm{mg}$ biomass). After static incubation and agitation, the growth curve of E. faecalis decreased. On the contrary, the growth curve of $C$. indologenes was constant with specific growth rate of 0.05 (Fig 2 and 3). Surprisingly, C. indologenes could grow in supernatant culture of E. faecalis (Fig 2), without lag phase.

Table 1 The growth characteristic and Orange II decolorization ability of E. faecalis and C. indologenes on Orange II containing media under static and agitated incubation

\begin{tabular}{|c|c|c|c|c|}
\hline \multirow{3}{*}{$\begin{array}{c}\text { The growth characteristics } \\
\text { and Orange II } \\
\text { decolorization ability }\end{array}$} & \multicolumn{4}{|c|}{ Species of bacteria } \\
\hline & \multicolumn{2}{|c|}{ E. faecalis } & \multicolumn{2}{|c|}{ indologenes } \\
\hline & Static & Agitated & Static & Agitated \\
\hline Spesific growth rate $\left(i \mathrm{~h}^{-1}\right)$ & 0.19 & ND & 0.16 & 0.05 \\
\hline Biom & 35.54 & ND & 24.11 & 17.18 \\
\hline Decolorization $\mathrm{r}$ & 11.02 & ND & 0.19 & ND \\
\hline $\begin{array}{l}\text { Decreased of Orange II } \\
\text { concentration }(\mathrm{mg} / \mathrm{l})\end{array}$ & 66.10 & ND & 1.16 & ND \\
\hline
\end{tabular}

$\mathrm{ND}=$ not determined 